\title{
Crystallization Kinetics of Precipitating Calcium from Yellow Phosphorus Slag Lixivium ${ }^{* *}$
}

DOI: $10.15255 /$ KUI.2013.029

KUI-26/2014

Short communication

Received September 5, 2013

Accepted December 12, 2013

\author{
G.-B. Li, ${ }^{\text {a } D . ~ M . ~ L u O, ~}{ }^{\text {a H. }}$-P. Li, ${ }^{\text {a } Y . ~ S u, ~}{ }^{\text {a* }}$ and M.-M. Du ${ }^{\mathrm{b}}$ \\ a Institute of Chemical Engineering, Kunming University of Science and Technology, \\ 650500 Kunming, Yunnan, PR China \\ ${ }^{\mathrm{b}}$ Faculty of foreign languages and cultures, Kunming University of Science and Technology, \\ 650500 Kunming, Yunnan, PR China
}

\begin{abstract}
The crystallization dynamic parameters of calcium sulphate were determined in the course of the precipitation conversion process of calcium in lixivium. The crystallization dynamic equations of calcium sulphate were achieved by multiple linear regression. The study results indicate that $\mathrm{CaSO}_{4} \cdot 2 \mathrm{H}_{2} \mathrm{O}$ crystal nucleation-growth kinetics equation in nitric acid leaching liquid of yellow phosphorus slag at room temperature is expressed by $B^{0}=2.904 \cdot 10^{11} \cdot G^{0.83} \cdot M_{\mathrm{T}}^{0.167}$.
\end{abstract}

Key words: Crystallization kinetics, yellow phosphorus slag lixivium, calcium sulphate, precipitation

\section{Introduction}

Yellow phosphorus slag is a solid waste obtained in the production of yellow phosphorus in electrical furnace in which the main ingredients are $\mathrm{SiO}_{2}$ and $\mathrm{CaO}$. It can be used for preparing silicon and calcium products with high added value. Studied were the kinetic characteristics of calcium sulphate crystallization in nitric acid lixivium formed in the course of treating yellow phosphorus slag with nitric acid solution. The crystallization kinetics parameters of calcium sulphate were determined.

At present, yellow phosphorus slag is used mainly as silicon fertilizer, cement, calcium phosphorous slag brick, porcelain tiles, microcrystal glass, white carbon black, and so on. ${ }^{1-8}$

The calcium in yellow phosphorus slag can be separated in the form of soluble calcium nitrate into solution. After separating the calcium and silicon, high quality white carbon black product with high added value can be obtained by leaching yellow phosphorus slag with nitric acid solution. ${ }^{9}$ In the meantime, we treated the lixivium containing calcium nitrate with sulphuric acid solution in order to obtain calcium sulphate of high purity and quality, and convert the calcium nitrate solution into nitric acid solution which can be used to leach yellow phosphorus slag so as to implement the recycle of lixivium. The paper studied the kinetics characteristics of calcium sulphate crystallization in nitric acid lixivium in the course of treating the yellow phosphorus slag with nitric acid solution.

\footnotetext{
* Corresponding author: Prof. Yi Su, e-mail: suyi0311@163.com

*** This manuscript is supported by CNSF Grant \#21066003.
}

\section{Experimental}

\section{Experimental techniques}

The crystallization process of calcium sulphate is composed of nucleation and crystal growth, and the kinetic characteristics of crystallization are controlled by the nucleation rate and linear growth rate of crystal together. The crystal nucleus formation has the form of primary nucleation and secondary nucleation, ${ }^{10}$ and the secondary nucleation is applied mostly in the course of industrial crystallization for it consumes less energy, produces crystals easily, and increases the yield of the product.

In general, the secondary nucleation is the controlling step in the crystallization process. ${ }^{11}$ The nucleation rate $B^{0}$ approximately equals to the secondary nucleation rate, $B_{\mathrm{s}}$, and it can be described by formula

$$
B^{0}=k_{\mathrm{n}} G^{i} M_{\top}^{j}
$$

where $M_{\mathrm{T}}$ is crystal mass concentration, ${ }^{12} k_{\mathrm{n}}$ is rate constant, $G$ is the crystal growth rate, $i$ and $j$ are empirical kinetic parameters which can be determined by regression analysis with experimental data.

The crystal growth rate is relevant with nucleation rate $B^{0}$ and crystal number density $n^{0}$. It can be expressed by formula

$$
B^{0}=n^{0} G
$$

The research pointed out that in a certain concentration of crystal slurry, the mass distribution of the crystal particles with different sizes was related to the crystal number density. The calculation relationship was as follows: ${ }^{11}$ 


$$
n=\lim _{\Delta L \rightarrow 0} \frac{\Delta N}{\Delta L}=\frac{d N}{d L},
$$

where $L$ is particle size, $N$ is number concentration of particles in slurry, and $n$ is crystal number size density.

For crystallizer, ${ }^{13}$ if we can ignore the crystal slurry volume changing with time and the growth of crystal according to the $\Delta L$ law and the crystal coalescence and rupture in the course of crystallization process, the relationship between the mass distribution of the crystal particles of different sizes and the crystal number density can be described by formula

$$
n=\lim _{\Delta L \rightarrow 0} \frac{\Delta N}{\Delta L}=\frac{M_{\mathrm{T}} W_{i}}{k_{v} \rho_{\mathrm{c}} V_{i} \Delta V_{i}}
$$

where $w_{\mathrm{i}}$ is mass fraction of the particles in the particle size range, $\rho_{\mathrm{c}}$ is crystal density, $k_{v}$ is crystal shape coefficient, $V_{\mathrm{i}}$ is crystal volume.

The study shows that the relationship among the crystal linear growth rate, the crystallization time, the crystal size and the density of crystal nucleus numbers can be depicted by formula

$$
\ln n=\ln n^{0}-\frac{L}{G t} .
$$

The formula indicates the relationship between the crystal number density and the crystal linear growth rate. ${ }^{14}$ By means of plotting with the crystal size as the abscissa and In $n$ as the ordinate, we can obtain a straight line of which the slope equals to $-1 / \mathrm{Gt}$ and intercept equals to $\ln n^{0}$. So, the crystal growth rate $G$ and the crystal number density $n^{0}$ can be calculated on the basis of the test data in the course of crystallization.

According to eqs. (1) and (2), the test data in crystallization under different operating conditions, and by applying multiple linear regression, we can obtain the crystallization kinetics parameters $i, j, k_{\mathrm{n}}$ and the crystallization kinetics equation can be obtained.

\section{Experimental raw material and apparatus}

Nitric acid, sulphuric acid, ethanol (all pure for analysis); Precision electric mixer, Jintan Automation Instrument Factory, Jiangsu; Ultrasonic cleaning machine, Kunshan Ultrasonic Instruments Co. Ltd.; OMEC laser particle size analyser, Zhuhai OMEC Science and Technology Co. Ltd.

\section{Experimental method}

Sulphuric acid solution (20\%) was added into the lixivium and stirred for 10, 20, 30, 40, 50, and 60 minutes, respectively, at stirring speed of $250 \mathrm{~min}^{-1}$ at room temperature.

After the precipitating reaction was fulfilled based on retention time, $10 \mathrm{ml}$ of the suspension solution was quickly transferred into a previously dried and weighed sand core filter for filtering and washing with anhydrous alcohol, and then dried to constant weight in order to calculate the crys- tal mass concentration $M_{\mathrm{T}}$. At the same time, the remaining suspension slurry was filtrated rapidly, washed with alcohol and dried. The dried calcium sulphate was dispersed and measured in anhydrous ethanol with OMEC laser particle size analyser after the sample was ultrasonic stirred for 2 minutes. Then the crystal size distribution was obtained.

\section{Results and discussion}

The analysis of the relationship between crystal number density and particle size

According to the crystal size analysis data, crystal number density $n$ of each grade range can be calculated by the eq. (4) and the relationship diagram between the crystal number density and crystal size $L$ can be made. Fig. 1 is the relationship diagram between the crystal number density and particle size $L$ for 10 minutes residence time. It can be seen that the crystal number density decreases with the increase in particle size.

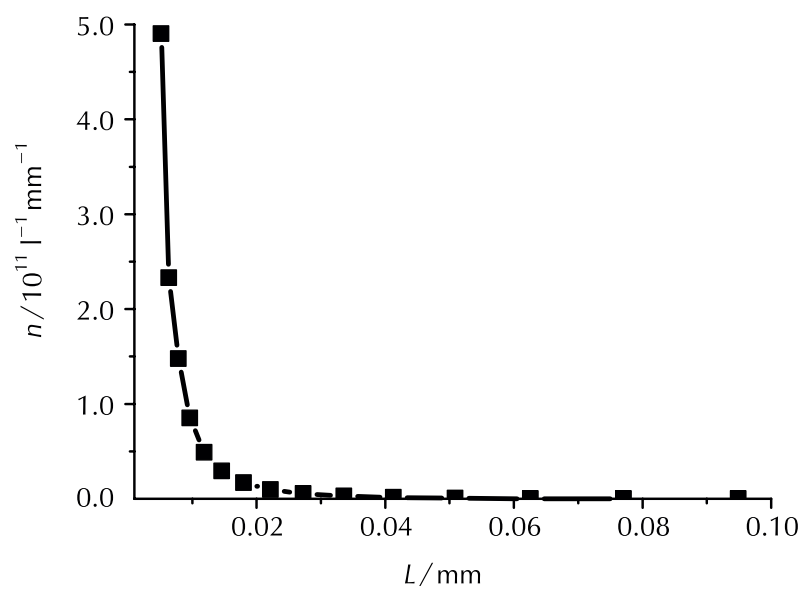

Fi g. 1 - Relation curve of crystal number size density $n$ and particle size $L$

SI i k a 1 -Odnos brojnosne gustoće veličine kristala $n$ i veličine čestica $L$

\section{The crystal nucleus number density and crystal growth rate}

According to eq. (5), the relationship between $\ln n$ and $L$ is linear in coordinate diagram of $\ln n$ and $L$, the slope equals to $-1 /$ Gt and the intercept equals to $\ln n^{0}$, so the crystal growth rate $G$ and crystal number density $n^{0}$ can be calculated on the basis of the test data in the course of calcium sulphate crystallization.

Fig. 2 shows the relation curve between $\ln n$ and $L$ for 10 minutes residence time and a linear regression straight line is obtained. It can be seen from Fig. 2 that the $1 / \mathrm{Gt}$ is 0.1514 and $\ln n^{0}=27.09$ in which the $G$ equals to $0.66 \mathrm{~mm} \mathrm{~min}^{-1}$ and $n^{0}=5.82 \cdot 10^{11} \mathrm{I}^{-1} \mathrm{~mm}^{-1}$. With the same method, the $G$ and $n^{0}$ of the residence time of 20,30, 40, 50, and 60 minutes can be obtained and the calculation results are expressed in Table 1. 
Ta b I e 1 - Results of the experimental data processing

Ta b I i c a 1 - Rezultati obrade eksperimentalnih podataka

\begin{tabular}{c|c|c|c|c|c}
\hline$\frac{t}{\min }$ & $\frac{G}{\mathrm{~mm} \mathrm{~min}^{-1}}$ & $\ln n^{0}$ & $\frac{n^{0}}{10^{11} \mathrm{I}^{-1} \mathrm{~mm}^{-1}}$ & $\frac{M_{\mathrm{T}}}{\mathrm{gl}^{-1}}$ & $\frac{B^{0}}{10^{11} \mathrm{I}^{-1} \mathrm{~min}^{-1}}$ \\
\hline 10 & 0.661 & 27.090 & 5.822 & 27.13 & 3.450 \\
20 & 0.338 & 27.121 & 6.005 & 28.13 & 2.030 \\
30 & 0.225 & 27.219 & 6.623 & 32.99 & 1.489 \\
40 & 0.176 & 27.618 & 9.871 & 42.03 & 1.273 \\
50 & 0.136 & 27.436 & 8.146 & 30.24 & 1.109 \\
60 & 0.112 & 27.335 & 6.730 & 29.96 & 0.755 \\
\hline
\end{tabular}

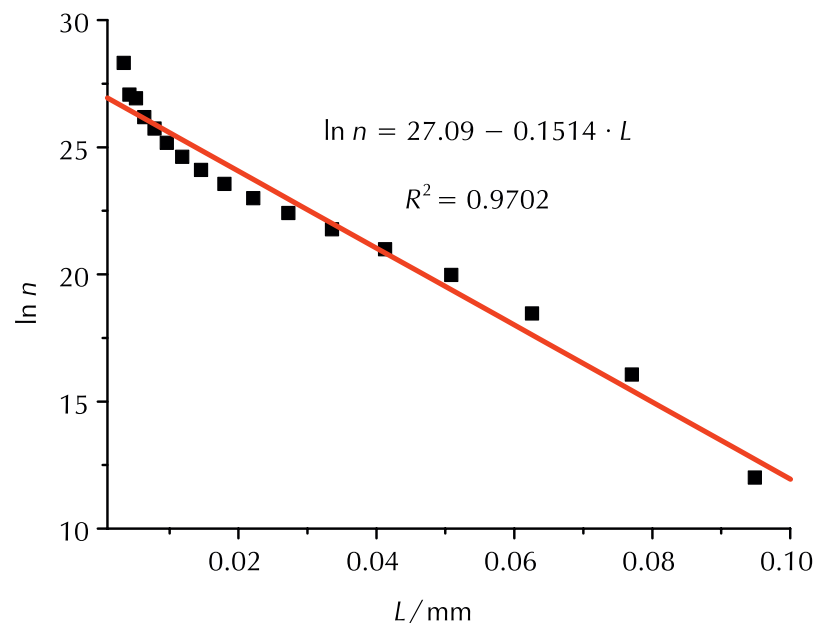

F i g . 2 - Relation curve between logarithm of crystal number size density In $n$ and particle size $L$

S I i k a 2 - Odnos logaritma brojnosne gustoće veličine kristala In $n i$ veličine čestica $L$

\section{The effect of residence time on the crystal growth rate $G$ and the nucleation rate $B^{0}$}

According to the crystal theory, the degree of supersaturation is an important effect factor of the crystal growth rate and crystal number density for most of the substances in the process of crystallization. Fig. 3 shows the relationship between residence time and the crystal growth rate G. Fig. 4 is the relationship diagram between the residence time and the nucleation rate $B^{0}$. It can be seen from Table 1 and Fig. 3 that the crystal growth rate gradually decreases with extending of residence time. According to Fig. 4, it can be seen that the calcium sulphate crystal nucleation rate reduces with the increase in residence time. This is mainly because the amount of calcium sulphate crystal increases, the crystal grows gradually and the supersaturation degree of the solution gradually reduces with the extension of residence time.

\section{Mathematical model of crystallization kinetics}

The $G$ and $n^{0}$ calculated under the condition of different residence time, the nucleation rate $B^{0}$ calculated by eq. (2) and the crystal mass concentration in suspension $M_{\mathrm{T}}$ are listed in Table 1. Based on the data of $B^{0}, M_{\mathrm{T}}$ and $G$ in Table 1 and crystal nucleation-growth kinetics equation described by eq. (1), the indices $i=0.83$ and $j=0.167$, and coefficient

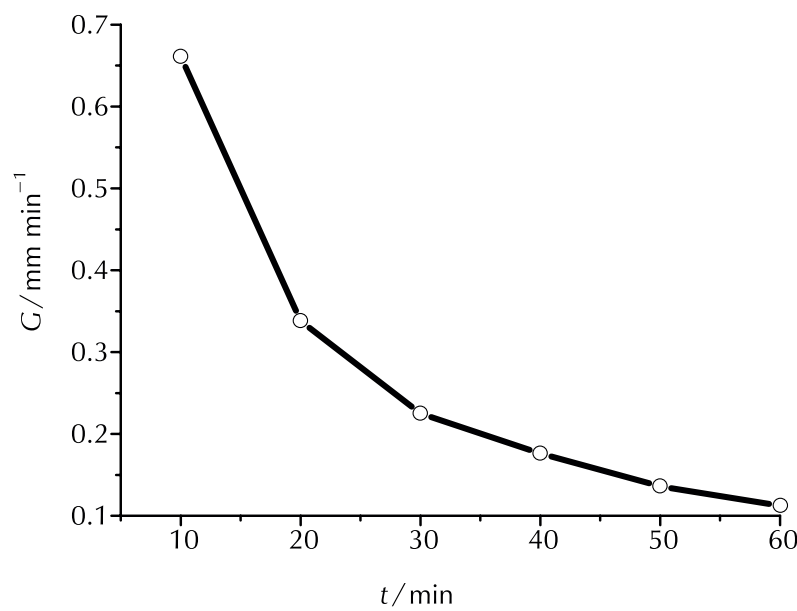

F i g . 3 - Relationship between residence time $t$ and the crystal growth rate $G$

S I i k a 3 - Odnos između trajanja reakcije i brzine kristalnog rasta

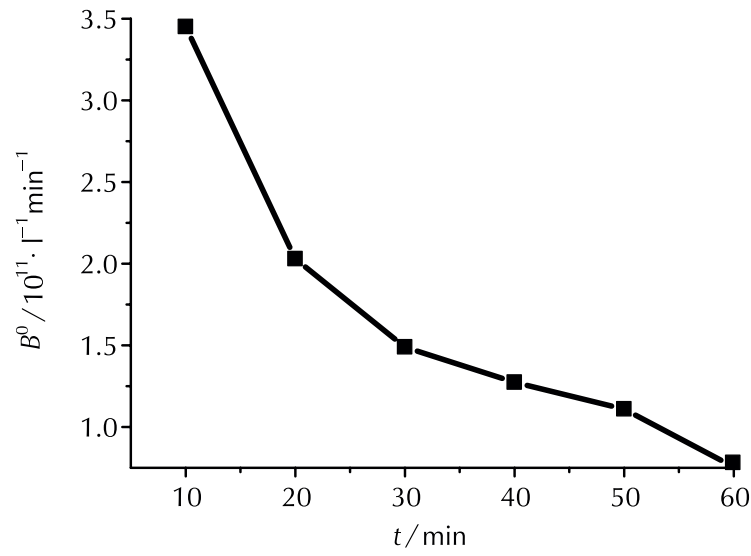

Fig . $\quad 4$-Relationship between residence time $t$ and nucleation rate $B^{0}$

S I i k a 4 -Odnos između trajanja reakcije t i brzine nukleacije $B^{0}$

$k_{\mathrm{n}}=2.904 \cdot 10^{11}$ were obtained by the multiple linear regression method. The $\mathrm{CaSO}_{4} \cdot 2 \mathrm{H}_{2} \mathrm{O}$ crystallization nucleation-growth kinetics equation in nitric acid leaching liquid of yellow phosphorus slag was obtained under the condition of room temperature:

$$
B^{0}=2.904 \cdot 10^{11} \cdot G^{0.83} \cdot M_{\mathrm{T}}^{0.167} .
$$




\section{Conclusion}

(1) The crystal nucleation rate and growth rate of calcium sulphate decreases with the increase in residence time in the course of precipitating calcium sulphate from nitrate leaching solution of the yellow phosphorus slag with sulphuric acid.

(2) The experimental study shows that the $\mathrm{CaSO}_{4} \cdot 2 \mathrm{H}_{2} \mathrm{O}$ crystallization kinetics indices $i=0.83, j=0.167$, which indicates that the effect of suspension density on the nucleation rate is not obvious and the effect of crystal growth rate on the nucleation rate is conspicuous.

(3) The $\mathrm{CaSO}_{4} \cdot 2 \mathrm{H}_{2} \mathrm{O}$ crystal nucleation-growth kinetics equation in nitric acid leaching liquid of yellow phosphorus slag at room temperature is expressed as follows:

$B^{0}=2.904 \cdot 10^{11} \cdot G^{0.83} \cdot M_{\mathrm{T}}^{0.167}$.

\section{List of symbols \\ Popis simbola}

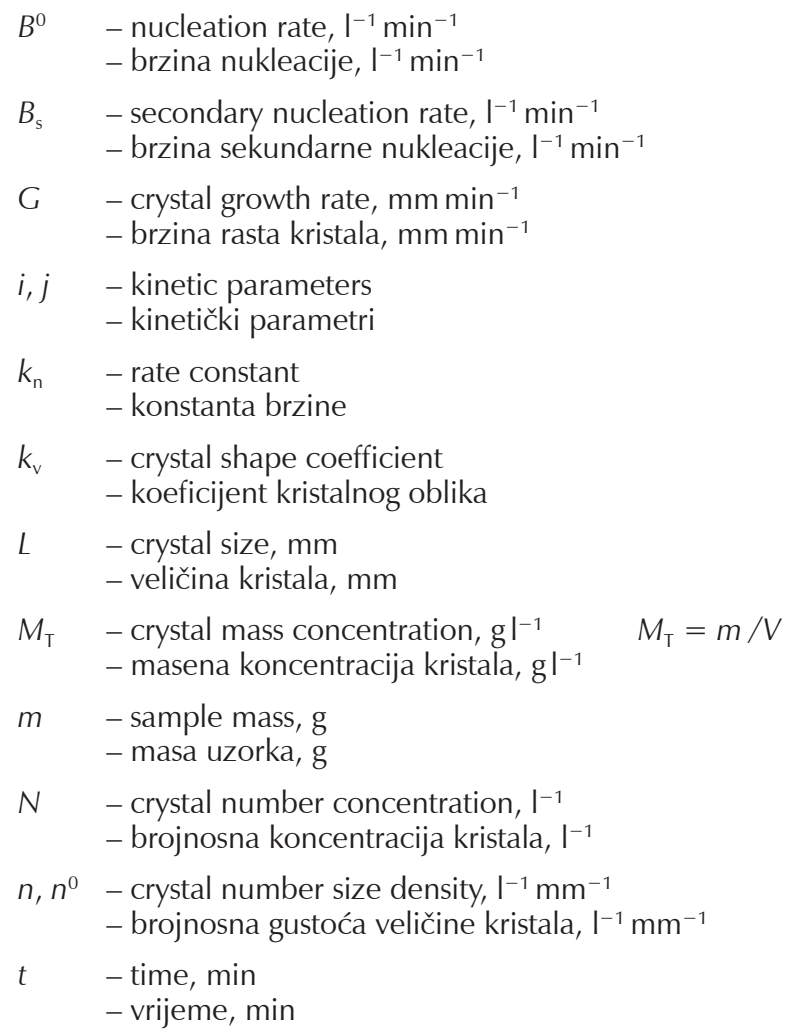

$V_{\mathrm{i}} \quad$ - crystal volume, $\mathrm{mm}^{3} \quad V_{\mathrm{i}}=L_{\mathrm{i}}{ }^{3}$

- obujam kristala, $\mathrm{mm}^{3} \quad \Delta V_{\mathrm{i}}=L_{\mathrm{i}+1}{ }^{3}-L_{\mathrm{i}}^{3}$

$w_{\mathrm{i}} \quad-$ mass fraction in the crystal size range, $\%$

- maseni udjel frakcije u rasponu veličine kristala, \%

$\rho_{\text {c }} \quad-$ crystal density, $\mathrm{gl}^{-1}$

- gustoća kristala, $\mathrm{gl}^{-1}$

\section{References}

Literatura

1. X. W. Gao, Y. S. Wu, The Current Comprehensive Utilization and Developing Tendency of Phosphorus Slag, Chin. Resour. Compr. Utili. 1 (2010) 28-30.

2. Y. Zhang, J. X. Cao, L. Yang, Progress on Comprehensive Reclamation Utilize of Phosphorous Slag, Guizhou Chem. Ind. 2 (2010) 27-30.

3. N. Q. Feng, Y. X, Shi, J. T. Ding, Properties of Concrete with Ground Ultrafine Phosphorus slag, Cem., Concr. and Aggr. 2 (2000) 128-132.

4. Y. Su, G. B. Li, J. P. Xia, Kinetic Study of Fe Removal From Precipitated Silica Prepared From Yellow Phosphorus Slag, Can. J. Chem. Eng. 87 (2009) 610-614, doi: http://dx.doi. org/10.1002/cjce.20197.

5. Y. Su, G. B. Li, J. P. Xia, X. W. Yang, Process of Preparing Precipitated Silica and $\mathrm{CaHPO}_{4} \cdot 2 \mathrm{H}_{2} \mathrm{O}$ With Yellow Phosphorus Slag, Environ. Eng. 5 (2008) 98-100.

6. Q. Lin, J. X. Cao, C. B. Fu, Y. Zhang, Development of Glass Ceramic by Sintering and Crystallization of Glass from Phosphorus Slag, Key Eng. Mat. 3 (2007) 1892-1894, doi: http:// dx.doi.org/10.4028/www.scientific.net/KEM.336-338.1892.

7. Y. L. Ma, Y. Su, G. B. Li, Z. T. Zha, Experimental Study on Refining White Carbon by Yellow Phosphorus Slag, B. Chin. Ceram. Soc. 5 (2010) 1202-1205.

8. Y. Su, G. B. Li, J. P. Xia, Study on preparation of precipitated silica by leaching yellow phosphorus slag with phosphoric acid, Inorg. Chem. Ind. 11 (2007) 41-43.

9. Y. L. Ma, Y. Su, X. Y Kang, Z. T. Zha, Study on preparation of precipitated silica capability by leaching yellow phosphorus slag with nitric acid, New Chem. Mat. 4 (2011) 94-96.

10. X. H. Ding, Q. Tan, Gong Ye Jie Jin, Chemical industry press, Beijing, 1985.

11. T. L. Ye, Huagong Jiejing Guocheng Yuanli Ji Yingyong, Beijing Industrial University Press, Beijing, 2006.

12. H. Y. Jiang, Study on the Cooling Crystallization Process of Copper Sulfate Pentahydrate, Tianjin university, 2007.

13. A. D. Randolph, M. A. Larson, Theory of Particulate Process, Academic Press, New York, 1988.

14. H. H. Song, Y. Yan, X. L Wang, Y. Lu, Experimental Study on Crystallization Kinetics of $\mathrm{CaSO}_{4} \cdot 2 \mathrm{H}_{2} \mathrm{O}$, Sea-Lake Salt and Chemical Industry 6 (9-11) (2002) 21. 


\title{
SAŽETAK
}

Kinetika kristalizacije kalcija izluženog iz troske bijelog fosfora

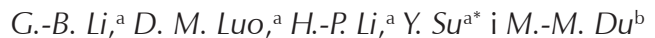

Određeni su parametri kinetike kristalizacije kalcijeva sulfata prilikom taloženja kalcija iz luga troske bijelog fosfora. Jednadžbe brzine kristalizacije kalcijeva sulfata dobivene su višestrukom linearnom regresijom. Kinetika kristalizacije $\mathrm{CaSO}_{4} \cdot 2 \mathrm{H}_{2} \mathrm{O}$ pri sobnoj temperaturi u dušično-kiselom lugu troske bijelog fosfora slijedi izraz $B^{0}=2.904 \cdot 10^{11} \cdot G^{0.83} \cdot M_{\mathrm{T}}^{0.167}$.

anstitute of Chemical Engineering,

Prispjelo 5. rujna 2013.

Kunming University of Science and Technology,

ćeno 12. prosinca 2013.

650500 Kunming, Yunnan, Kina.

${ }^{\mathrm{b}}$ Faculty of foreign languages and cultures,

Kunming University of Science and Technology,

650500 Kunming, Yunnan, Kina. 